\title{
Problematic Internet Use (PIU) Among Adolescents during COVID-19 Lockdown: A Study of High School Students in Ibadan, Nigeria
}

\section{Olayinka Stephen Ilesanmi}

Lecturer, Department of Community Medicine, University of Ibadan, Nigeria

(iD https://orcid.org/0000-0003-0827-6442

\section{Aanuoluwapo Adeyimika Afolabi \\ MPH Candidate, Department of Community Medicine, University of Ibadan, Nigeria \\ (iD https://orcid.org/0000-0001-9928-2252}

\author{
Ayodeji Matthew Adebayo \\ Senior Lecturer, Department of Community Medicine, University of Ibadan, Nigeria \\ iD https://orcid.org/0000-0002-9912-100X
}

\begin{abstract}
Problematic internet use (PIU) has generally been strongly associated with depression and attention deficit hyperactivity disorder, especially among adolescents, with resulting consequences for their health. This study explores the pattern of internet use, and the prevalence of PIU before and during the COVID-19 lockdown, as well as the causes, effects, and potential mitigation measures in respect of PIU during the lockdown, among high school students in Ibadan, Nigeria. A structured questionnaire, including a 20-question internet addiction test (IAT), was administered during the COVID-19 lockdown to 440 adolescents enrolled in high schools. Of these adolescents, $7.7 \%$ appeared from their responses to have had PIU before the COVID-19 lockdown period. However, 64.3\% of respondents appeared from their responses to have had PIU during the COVID-19 lockdown period. The main reasons for the increased PIU were boredom, loneliness, idleness, pleasure gained from internet use, physical isolation, and the need for information and communication. The effects of PIU reported among the adolescents included reduced family intimacy, poor academic performance, loss of concentration, as well as internet abuse and risky sexual behaviour. To mitigate PIU among high school students, parental monitoring of adolescents, and their internet access and use, should be promoted. In addition, programmes should be organised by the media and academic institutions to keep adolescents engaged in productive tasks.
\end{abstract}

\section{Keywords}

problematic internet use (PIU), internet addiction test (IAT), adolescents, high school students, COVID-19, lockdown, Ibadan, Nigeria 


\section{Acknowledgements}

The authors are grateful to all the adolescents who participated in the study. No external funding support was received for this study.

\section{Declaration}

The authors declare that they have no conflicts of interest.

\section{Authors' contributions}

OSI, AAA, and AMA conceptualised the study; OSI and AAA analysed the data; AAA wrote the first draft of the article; OSI and AMA reviewed and provided input on the draft; and all authors approved the final draft.

DOI: $\underline{\text { https://doi.org/10.23962/10539/31373 }}$

\section{Recommended citation}

Ilesanmi, O.S., Afolabi, A.A., \& Adebayo, A.M. (2021). Problematic internet use (PIU) among adolescents during COVID-19 lockdown: A study of high school students in Ibadan, Nigeria. The African Journal of Information and Communication (AJIC), 27, 1-22. https://doi.org/10.23962/10539/31373

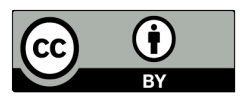

This article is licensed under a Creative Commons Attribution 4.0 International (CC BY 4.0) licence: https://creativecommons.org/licenses/by/4.0

\section{Introduction}

The outbreak of novel coronavirus disease (COVID-19), first documented in Wuhan, China in late 2019, was declared a public health emergency by the World Health Organisation in March 2020 (WHO, n.d.; Ilesanmi et al., 2021). As of 10 April 2021, COVID-19 had spread across 213 countries, with 135,945,439 confirmed cases and nearly 3 million deaths recorded globally (Afolabi \& Ilesanmi, 2021; Worldometer, n.d.). In Africa, recorded COVID-19 cases and fatalities were highest in South Africa, Morocco, Tunisia, Ethiopia, Egypt, Libya, and Nigeria (Worldometer, n.d.). As of 10 April 2021, Nigeria had documented 163,736 confirmed COVID-19 cases and 2,060 deaths (Worldometer, n.d.). The COVID-19 lockdown period increased the use of computers and the internet as indispensable tools for accessing information and enhancing relationships (Donohue \& Miller, 2020). Due to workplace closures, the internet has also been increasingly adopted as a viable means of economic 
activity and job retention. Online meetings, the virtual scheduling of religious activities, and online classes became routine during the lockdown period (Donohue \& Miller, 2020).

The internet is a technological tool which supports the growth of children and adolescents, and enhances research, intuition, problem solving skills, development of life skills, and critical thinking abilities (Cakmak \& Gul, 2018). However, when used in an uncontrolled, purposeless, and excessive manner, it can negatively influence the development of positive and protective habits (Cakmak \& Gul, 2018; Park et al., 2018). Problematic internet use (PIU) has been defined as a condition where an individual uses the internet excessively and cannot withdraw from the internet. The occurrence of PIU during the COVID-19 lockdown has been recognised in the literature (Király et al., 2020).

The occurrence of PIU could occur at any stage of life; however, adolescents are at the highest risk for its occurrence (Cakmak \& Gul, 2018). Adolescents are particularly vulnerable to PIU because of the rapid mental, emotional, and social developments occurring during this phase of life (Yang \& Tung, 2007; Ceyhan, 2008). Due to their quest for knowledge during this developmental period, adolescents are more attracted than any other age group to technological tools (Cakmak \& Gul, 2018). It has also been suggested that adolescents adopt internet usage as a means of substituting the challenges faced in real life with the euphoria obtained from the virtual world (Brown, 2006). PIU has generally been strongly associated with reduced sleeping time, the tendency to postpone sleep, insomnia, increased alertness, excessive tiredness, and depression (Brown, 2006; Park et al., 2018). The failure to address the possible effects of PIU and to suggest mitigating factors could result in impaired cognitive capacity among adolescents with a resulting decline in their productivity in later years. This could pose great threats to the overall safety and productivity of Nigeria and the entire world.

To the best of our knowledge, no research has been conducted regarding PIU among adolescents in Nigeria during the COVID-19 lockdown. According to the Nigeria Demographic Health Survey, $15.6 \%$ of adolescents aged 15 to 19 years use the internet; most of them reside in urban settings (NPC \& ICF, 2019). Research on the causes and effects of PIU is important to the development of further guidelines regarding PIU and its management while coping during a lockdown. This study therefore aimed to assess the pattern of internet use, and the prevalence of PIU before and during the COVID-19 lockdown, as well as the causes, effects, and potential mitigation measures for PIU during the COVID-19 lockdown among high school students in the Nigerian city of Ibadan. 


\section{Research design}

\section{Study sample}

The research took place during COVID-19 lockdown-between 27 July and $7 \mathrm{Au}-$ gust 2020 - in Ibadan, the capital of Oyo State. The study population consisted of adolescents in selected communities in the city. A minimum sample size of 460 was estimated for this study, using the Leshlie Kish formula for cross-sectional studies. (We used an estimated prevalence of 50\%, a precision value of $5 \%$ due to the unavailability of sample size calculation in existing PIU literature, and a 20\% non-response rate.)

All eligible adolescents aged 10 to 18 years who provided consent were included in the study. A two-stage sampling technique was used to enrol respondents. In the first stage, a simple random sampling method was used to select four of the 11 local government areas (LGAs) in Ibadan: Ibadan South-East, Ibadan South-West, Ibadan North, and Ibadan North-East. In the second stage, we selected a political ward from each of the four selected LGAs, again using a simple random sampling technique. In each of the four selected wards, a centre location was identified, and a bottle was rotated once on a map to determine the areas to be targeted in seeking interviewees. From the areas corresponding to the direction of the bottle tip, all eligible adolescents were included in the study. First, each adolescent was approached in their household and asked if they were enrolled in high school before the COVID-19 lockdown. All adolescents who provided positive responses about their school enrolment, and who were confirmed to be users of the internet, were then informed about the purpose of the study. (All those who were not enrolled in high school before the lockdown were excluded.) Respondents were informed that they had the right to withdraw from the study at any time. All participants were assured that all information obtained would remain confidential. Eligible but unwilling adolescents were excluded.

Consent was obtained from each participating adolescent, and from a parent or an adult who could make decisions for the adolescent in the absence of a parent. Of the 460 eligible participants approached, we obtained permission and consent for 440 adolescents, thus yielding a response rate of $95 \%$. No harm was inflicted on participants as a result of their participation in this study.

\section{Data collection instrument}

A structured, interviewer-administered questionnaire was used for data collection (see questionnaire in Appendix). The questionnaire covered the following:

- sociodemographic characteristics of the respondents and their parents (closed-ended questions);

- pattern of internet use (closed-ended questions);

- causes, effects, and factors associated with PIU during COVID-19 lockdown (open-ended questions); 
- $\quad$ strategies to mitigate PIU during COVID-19 lockdown (open-ended questions); and

- an internet addiction test (IAT), which generated a PIU scale (see Appendix).

The IAT is a 20-question tool, developed by Young (see Young \& Rogers, 2009). The IAT has been validated in literature as a standard tool for assessing PIU and internet addiction, including among adolescents and young adults in Nigeria (Oshodi et al., 2012). A shift in paradigm has informed a trend towards focusing on PIU rather than internet addiction. Internet addiction describes uncontrolled engagement in online activities that offer no benefit to the user. PIU, meanwhile, allows for the reality that an online activity may ordinarily provide benefits to the user, but its excessive use can result in negative consequences. To date, there is no consensus on a tool to measure PIU; hence, the IAT is still being used to assess PIU.

Using the IAT tool, 20 questions were asked on elements associated with PIU, both before and during the COVID-19 lockdown. These included questions such as the frequency of staying online longer than intended, the frequency of neglecting household chores to spend more time online, the frequency of sleep loss due to late night $\log$-ins, the frequency of hiding the length of time spent online, the frequency of feeling depressed or moody while offline, and the frequency of a decline in school grades or work performance. In addition to these, we asked questions about the frequency of being secretive about the online activity being engaged in, the frequency of prioritising email checks, the frequency of anticipating the next online schedule, the frequency of receiving complaints from others due to the time spent online, and the frequency of saying "just a minute more" when online. Other questions were asked about the frequency of preferring the internet to family intimacy, the failure to reduce time spent online, and the frequency of snapping or yelling when offline. A slight modification in the IAT was made to capture two different periods: before the COVID-19 lockdown, and during the lockdown.

\section{Data collection}

Data were collected by trained research assistants (RAs) who had all obtained at least a Bachelor's degree. The RAs were trained on data collection for two days, on 25 and 26 July 2020. The questionnaire was pre-tested among adolescents in a community that was not selected for this study. After this pre-test, a few questions were modified.

Ethical approval for this study was obtained from the Oyo State Ministry of Health Ethical Review Committee, with reference number AD/13/479/1779A.

\section{Data analysis}

Data analysis was done using SPSS version 23. Mean and standard deviation were used to summarise quantitative continuous variables such as age, while frequencies and percentages were used to summarise categorical variables such as age group. 
The pattern of internet use, the number of hours of daily internet access, the average time spent online per day, and the age of onset of internet use were computed using mean and standard deviation. Other details, such as the reasons for going online and the activities engaged in during the immediate past 24 hours, were also computed using frequency tables. Open-ended questions were asked about the causes of PIU, the effects of PIU, and strategies to reduce PIU. Closely related responses were grouped together when analysing the responses to these questions. Bivariate analysis was conducted using the Chi-square test, the t-test, and Pearson correlation. Pearson correlation was used to determine the strength of association between time spent online per day with sociodemographic and other internet use variables. Among the relationships of interest were the sociodemographic determinants of PIU before and during the COVID-19 lockdown, and associations between time spent online per day and sociodemographic characteristics. Statistically significant variables using Chi-square tests were used for the logistic regression model. The level of statistical significance was $\mathrm{p}<0.05$.

To determine the prevalence of PIU, IAT scores for each of the 20 questions in the IAT were computed using the frequency of occurrence of each symptom of PIU. A score of "0" was assigned for "not applicable", "1" for "rarely", "2" for "occasionally", "3" for "frequently", " 4 " for "often", and " 5 " for "always". Thus, the maximum IAT score for each of the two periods - the pre-lockdown period and the lockdown periodwas 100 points across. Cumulative IAT scores ranging between 20 and 49 points were treated as evidence of "complete ability to control/limit one's level of internet use". Cumulative scores between 50 and 70 points were treated as suggestive of "occasional PIU" (i.e., occasional inability to control/limit one's level of internet use). Cumulative IAT scores greater than 70 points were seen as suggesting "significant PIU” (i.e., significant inability to control/limit one's level of internet use).

\section{Findings}

\section{Respondents'sociodemographic characteristics}

A total of 440 respondents were interviewed, with a mean age of $14.15 \pm 1.99$ years. Of the respondents, 217 (49.3\%) were males, 218 (49.5\%) had attained junior high school, and $262(59.5 \%)$ had three or fewer siblings. Other sociodemographic characteristics are as shown in Table 1. 
Table 1: Sociodemographic characteristics of surveyed adolescents

\begin{tabular}{|c|c|c|}
\hline Variable & Frequency & $\%$ \\
\hline \multicolumn{3}{|l|}{ Age group (years) } \\
\hline $10-12$ & 88 & 20 \\
\hline $13-15$ & 238 & 54.1 \\
\hline $16-18$ & 114 & 25.9 \\
\hline \multicolumn{3}{|l|}{ Sex } \\
\hline Male & 217 & 49.3 \\
\hline Female & 223 & 50.7 \\
\hline \multicolumn{3}{|l|}{ Current enrolment level } \\
\hline Junior high school & 218 & 49.5 \\
\hline Senior high school & 222 & 50.5 \\
\hline \multicolumn{3}{|l|}{ Mother's age group (years) } \\
\hline Less than 45 & 184 & 41.8 \\
\hline 45 and above & 256 & 58.2 \\
\hline \multicolumn{3}{|l|}{ Father's age group (years) } \\
\hline Less than 45 & 62 & 14.1 \\
\hline 45 and above & 378 & 85.9 \\
\hline \multicolumn{3}{|l|}{ Father's education level } \\
\hline Primary school or below & 36 & 8.2 \\
\hline High school or above & 404 & 91.8 \\
\hline \multicolumn{3}{|l|}{ Mother's education level } \\
\hline Primary school or below & 74 & 16.8 \\
\hline High school or above & 366 & 83.2 \\
\hline \multicolumn{3}{|l|}{ Person lived with } \\
\hline Parent & 389 & 88.4 \\
\hline Guardian & 51 & 11.6 \\
\hline \multicolumn{3}{|l|}{ Number of siblings } \\
\hline Three or fewer & 262 & 59.5 \\
\hline Four or more & 178 & 40.5 \\
\hline
\end{tabular}




\section{Pattern of internet use}

Smartphones were the most owned device, owned by 369 respondents (98.1\%). Smartphones were also the most used internet access device, used by 368 respondents (97.9\%), and the most common point of internet access was the smartphone, cited by 347 respondents (92.3\%). The most frequently cited reason for going online during the lockdown was socialising, cited by 331 respondents (88\%), and the most used social networking platforms were Facebook (used by 359 respondents (95.5\%)) and WhatsApp (used by 338 respondents (89.9\%)). More than a half of respondents (64.2\%) used the internet daily (see Table 2).

Table 2: Pattern of internet use

\begin{tabular}{|c|c|c|}
\hline Characteristics of internet use & Frequency & $\%$ \\
\hline \multicolumn{3}{|l|}{ Devices currently owned* } \\
\hline Smartphone & 369 & 98.1 \\
\hline Gaming device & 76 & 20.2 \\
\hline Tablet & 26 & 6.9 \\
\hline Laptop & 11 & 2.9 \\
\hline Desktop computer & 3 & 0.8 \\
\hline \multicolumn{3}{|l|}{ Devices used for internet access* } \\
\hline Smartphone & 368 & 97.9 \\
\hline Gaming device & 45 & 12 \\
\hline Tablet & 25 & 6.6 \\
\hline Laptop & 10 & 2.7 \\
\hline Desktop computer & 4 & 1.1 \\
\hline \multicolumn{3}{|l|}{ Internet points of access* } \\
\hline Personal smartphone & 347 & 92.3 \\
\hline Home & 37 & 9.8 \\
\hline Paid hotspots & 5 & 1.3 \\
\hline School & 3 & 0.8 \\
\hline Free public hotspots & 2 & 0.5 \\
\hline \multicolumn{3}{|l|}{ Reasons for going online* } \\
\hline Socialising & 331 & 88 \\
\hline Communication & 266 & 70.7 \\
\hline School assignment & 227 & 60.4 \\
\hline Information research & 119 & 31.6 \\
\hline
\end{tabular}




\begin{tabular}{|c|c|c|}
\hline Internet social networking tools used $^{*}$ & & \\
\hline Facebook & 359 & 95.5 \\
\hline WhatsApp & 338 & 89.9 \\
\hline Snapchat & 40 & 10.6 \\
\hline Twitter & 40 & 10.6 \\
\hline Instagram & 28 & 7.4 \\
\hline Eskimi & 1 & 0.3 \\
\hline Daily internet use & & \\
\hline Yes & 79 & 64.2 \\
\hline No & 44 & 35.8 \\
\hline
\end{tabular}

$*$ Multiple responses allowed

As seen in Figure 1, 391 respondents (88\%) had, in the past 24 hours, engaged in chatting with friends, while $263(69.9 \%)$ had engaged in internet social networking. Reading magazines and books was also cited by 144 (38.3\%), while watching movies, serials and videos was cited by 141 individuals (37.5\%).

Figure 1: Online activities during the preceding 24 hours (during lockdown)

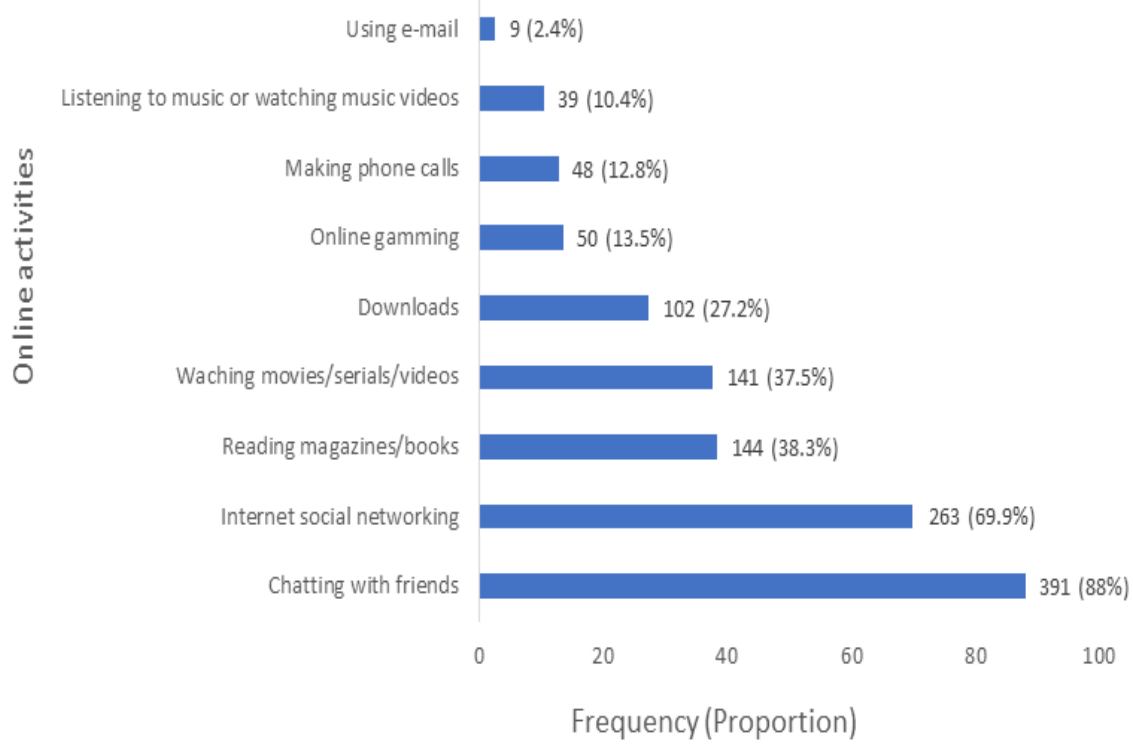




\section{Pattern of PIU before and during the lockdown}

As seen in Figure 2, the IAT test scores at the time of the survey suggest that 347 respondents $(92.3 \%)$ believed they had the complete ability to control their internet use (defined as cumulative IAT scores from 0 to 49 points) during the pre-lockdown period. In contrast, only 134 (35.6\%) felt they had the complete ability to control their level of use during lockdown. Before the lockdown, only 28 respondents (7.4\%) had occasional PIU (defined as cumulative IAT scores ranging between 50 and 70 points). This figure rose during lockdown to 167 respondents (44.4\%) having occasional PIU. Only one respondent (0.3\%) had significant PIU (defined as cumulative IAT scores greater than 70 points) before the COVID-19 lockdown. This number rose during the lockdown to 75 respondents (19.9\%) with significant PIU (Figure 2).

Aggregating the findings of occasional and significant PIU, 29 respondents (7.7\%) appeared from their responses to have had PIU before the COVID-19 lockdown, while 242 (64.3\%) appeared from their responses to have had PIU during the lockdown. The mean score of PIU before the lockdown was $30.15 \pm 14.13$, while the mean score of PIU during the lockdown was $54.49 \pm 18.89(\mathrm{t}=-44.183, \mathrm{p}=0.001)$.

\section{Figure 2: PIU incidence before and during lockdown}

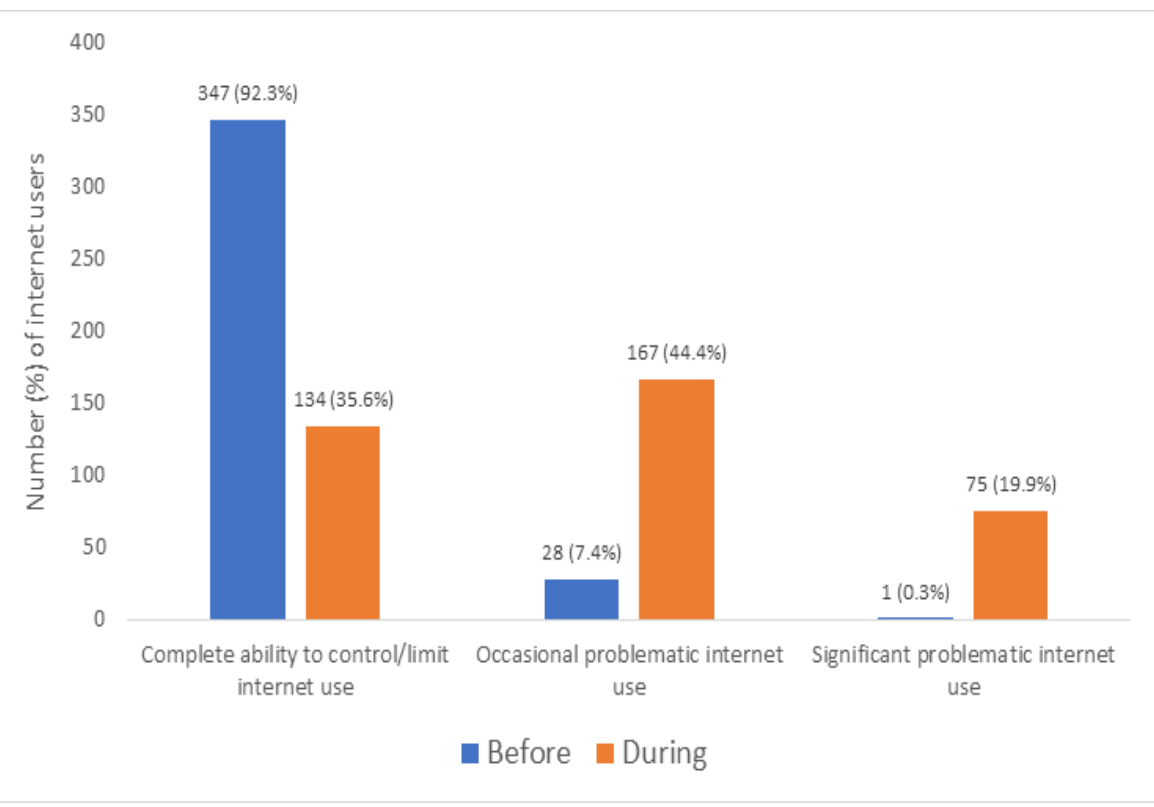




\section{PIU causes, effects and mitigation during the lockdown}

As seen in Table 3,142 adolescents (32.3\%) cited loneliness or physical isolation as the causes of PIU during the lockdown period. Other causes of PIU stated included poor discipline as cited by 99 (22.5\%), and socialising, communication, and pleasure derived from online activities, as cited by 66 (15\%). In terms of the effects of PIU, $118(26.8 \%)$ mentioned reduced family intimacy, and 102 (23.2\%) noted poor academic performance, and loss of concentration. In addition, 95 adolescents (21.6\%) stated that PIU could result in internet abuse or risky sexual behaviour. When asked about the ways in which PIU could be mitigated, 286 respondents (65\%) suggested awareness-raising among, and/or monitoring of, adolescents; 136 (30.9\%) suggested ending the school closures; and 18 (4.1\%) suggested that adolescents should be engaged in more productive tasks.

Table 3: PIU causes, effects and mitigations during the COVID-19 lockdown

\begin{tabular}{|c|c|c|}
\hline Dimension & Frequency & \% \\
\hline Causes of PIU & & \\
\hline Loneliness, physical isolation & 142 & 32.3 \\
\hline Poor discipline & 99 & 22.5 \\
\hline $\begin{array}{c}\text { Socialising, communication, pleasure from online } \\
\text { activities }\end{array}$ & 66 & 15 \\
\hline Boredom & 60 & 13.6 \\
\hline Parental neglect & 41 & 9.3 \\
\hline Laziness, idleness & 32 & 7.3 \\
\hline $\begin{array}{c}\text { Effects of PIU } \\
\text { Reduced family intimacy }\end{array}$ & \\
\hline Poor academic performance, loss of concentration & 118 & 26.8 \\
\hline Internet abuse, risky sexual behaviour & 95 & 23.2 \\
\hline $\begin{array}{c}\text { Tiredness, loss of sleep, headaches, reduced eye func- } \\
\text { tioning }\end{array}$ & 74 & 21.6 \\
\hline Neglecting household chores & 51 & 16.8 \\
\hline $\begin{array}{c}\text { Suggestions of ways to mitigate PIU } \\
\text { Awareness-raising, monitoring }\end{array}$ & & \\
\hline Suspension of school closures & 136 & 30.9 \\
\hline & 18 & 4.1 \\
\hline Engagement of adolescents in more productive tasks & & \\
\hline
\end{tabular}




\section{Correlations between sociodemographic variables and PIU}

Table 4 shows the correlations between sociodemographic variables and PIU before and during the COVID-19 lockdown. In the pre-lockdown period, it was found that $13.4 \%$ of the adolescents aged 16 to 18 years had occasional or significant PIU (p $=0.019$ ), compared to only $5.9 \%$ of the $13-$ to 15 -year-olds and $2.3 \%$ of the 10 - to 12 -year-olds. During the lockdown, it was found that $86.6 \%$ of adolescents aged 16 to 18 had occasional or significant PIU ( $p=<0.001$ ), compared to $61.8 \%$ of the $13-$ to 15 -year-olds and $20.5 \%$ of the 10 - to 12 -year-olds. This suggests that older adolescents are more likely than younger adolescents to develop PIU in both non-lockdown and lockdown periods. In turn, 13- to 15-year-olds appear to be less susceptible to PIU than 16- to 18-year-olds, and more susceptible than 10- to 12-year-olds. Table 4 also shows a similar difference in PIU susceptibility between senior high school and junior high school students, with the senior high school students more susceptible during both the pre-lockdown and lockdown periods. In respect of gender differences, Table 4 shows that the male respondents were more susceptible to PIU than the female respondents, both pre-lockdown and during lockdown.

Table 4: Correlations between sociodemographic variables and PIU

\begin{tabular}{|c|c|c|c|c|}
\hline Variables & \multicolumn{2}{|c|}{ PIU pre-lockdown } & \multicolumn{2}{|c|}{ PIU during lockdown } \\
\hline & Present & Absent & Present & Absent \\
\hline & n (\%) & n (\%) & n (\%) & n (\%) \\
\hline \multicolumn{5}{|l|}{$\begin{array}{c}\text { Age group } \\
\text { (years) }\end{array}$} \\
\hline $10-12$ & $1(2.3)$ & $43(97.7)$ & $9(20.5)$ & $35(79.5)$ \\
\hline $13-15$ & $13(5.9)$ & $207(94.1)$ & $136(61.8)$ & $84(38.2)$ \\
\hline \multirow[t]{2}{*}{$16-18$} & $15(13.4)$ & $97(86.6)$ & $97(86.6)$ & $15(13.4)$ \\
\hline & \multicolumn{2}{|c|}{$\chi_{2}=7.912, p=\mathbf{0 . 0 1 9}$} & \multicolumn{2}{|c|}{$\chi^{2}=61.765, p=<\mathbf{0 . 0 0 1}$} \\
\hline \multicolumn{5}{|l|}{ Sex } \\
\hline Male & $20(10.9)$ & $163(89.1)$ & $123(67.2)$ & $60(32.8)$ \\
\hline \multirow[t]{2}{*}{ Female } & $9(4.7)$ & $184(95.3)$ & $119(61.7)$ & $74(38.3)$ \\
\hline & \multicolumn{2}{|c|}{$\chi^{2}=5.181, p=\mathbf{0 . 0 2 3}$} & \multicolumn{2}{|c|}{$\chi_{2}=1.264, p=0.261$} \\
\hline \multicolumn{5}{|l|}{$\begin{array}{l}\text { Current enrol- } \\
\text { ment level }\end{array}$} \\
\hline $\begin{array}{l}\text { Junior high } \\
\text { school }\end{array}$ & $6(3.8)$ & $154(96.2)$ & 67 (41.9) & $93(58.1)$ \\
\hline \multirow{2}{*}{$\begin{array}{l}\text { Senior high } \\
\text { school }\end{array}$} & $23(10.6)$ & $193(89.4)$ & $175(81.0)$ & $14(19.0)$ \\
\hline & \multicolumn{2}{|c|}{$\chi^{2}=6.945, p=\mathbf{0 . 0 1 3}$} & \multicolumn{2}{|c|}{$x^{2}=61.399, p=<\mathbf{0 . 0 0 0 1}$} \\
\hline $\begin{array}{l}\text { Father's age } \\
\text { group (years) }\end{array}$ & & & & \\
\hline
\end{tabular}




\begin{tabular}{|c|c|c|c|c|}
\hline Less than 45 & $3(6.4)$ & $44(93.6)$ & $24(51.1)$ & $23(48.9)$ \\
\hline 45 and above & $26(7.9)$ & $303(92.1)$ & $218(66.3)$ & $111(33.7)$ \\
\hline & \multicolumn{2}{|c|}{$\chi^{2}=0.133, p=0.715$} & \multicolumn{2}{|c|}{$\chi^{2}=4.141, p=\mathbf{0 . 0 4 2}$} \\
\hline \multicolumn{5}{|l|}{$\begin{array}{l}\text { Mother's age } \\
\text { group (years) }\end{array}$} \\
\hline Less than 45 & $8(5.3)$ & $143(94.7)$ & $83(55.0)$ & $68(45.0)$ \\
\hline \multirow[t]{2}{*}{45 and above } & $21(9.3)$ & $204(90.7)$ & $159(70.7)$ & $66(29.3)$ \\
\hline & \multicolumn{2}{|c|}{$\chi_{2}=2.067, p=0.151$} & \multicolumn{2}{|c|}{$\chi_{2}=9.710, p=\mathbf{0 . 0 0 2}$} \\
\hline \multicolumn{5}{|l|}{$\begin{array}{l}\text { Father's educa- } \\
\text { tion level }\end{array}$} \\
\hline $\begin{array}{l}\text { Primary school } \\
\text { or below }\end{array}$ & $3(11.1)$ & $24(88.9)$ & $19(70.4)$ & $8(29.6)$ \\
\hline \multirow{2}{*}{$\begin{array}{l}\text { High school or } \\
\text { above }\end{array}$} & $28(7.4)$ & $323(92.6)$ & $223(63.9)$ & $126(36.1)$ \\
\hline & \multicolumn{2}{|c|}{$\chi^{2}=0.472, p=0.492$} & \multicolumn{2}{|c|}{$\chi^{2}=0.458, p=0.499$} \\
\hline \multicolumn{5}{|l|}{$\begin{array}{l}\text { Mother's educa- } \\
\text { tion level }\end{array}$} \\
\hline $\begin{array}{c}\text { Primary school } \\
\text { or below }\end{array}$ & $6(10.9)$ & $41(89.1)$ & $38(68.1)$ & $17(30.9)$ \\
\hline \multirow{2}{*}{$\begin{array}{l}\text { High school or } \\
\text { above }\end{array}$} & $23(7.2)$ & $298(92.8)$ & $204(63.6)$ & $117(36.4)$ \\
\hline & \multicolumn{2}{|c|}{${ }^{x 2}=0.925, p=0.336$} & \multicolumn{2}{|c|}{$\chi^{2}=0.628, p=0.428$} \\
\hline \multicolumn{5}{|l|}{$\begin{array}{c}\text { Person lived } \\
\text { with }\end{array}$} \\
\hline Parent & $27(8.0)$ & $309(92.0)$ & $219(65.2)$ & $117(34.8)$ \\
\hline \multirow[t]{2}{*}{ Guardian } & $2(5.0)$ & $38(95.0)$ & $23(57.5)$ & $17(42.5)$ \\
\hline & \multicolumn{2}{|c|}{$\chi^{2}=0.463, p=0.496$} & \multicolumn{2}{|c|}{$\chi^{2}=0.919, p=\mathbf{0 . 0 3 8}$} \\
\hline \multicolumn{5}{|l|}{$\begin{array}{l}\text { Number of } \\
\text { siblings }\end{array}$} \\
\hline Three or fewer & $11(5.0)$ & $210(95.0)$ & $129(58.4)$ & $92(41.6)$ \\
\hline \multirow[t]{2}{*}{ Four or more } & $18(11.6)$ & $137(88.4)$ & $113(72.9)$ & $42(37.1)$ \\
\hline & \multicolumn{2}{|c|}{$\chi_{2}=5.636, p=\mathbf{0 . 0 1 8}$} & \multicolumn{2}{|c|}{$\chi_{2}=8.388, p=\mathbf{0 . 0 0 4}$} \\
\hline
\end{tabular}

Notes: ${ }^{x 2}=$ Chi-square test; $\mathrm{p}$-values in bold indicate finding is statistically significant $(\mathrm{p}<0.05)$

Table 5 shows that the male respondents were, before the lockdown, twice as likely as female adolescents to develop PIU (adjusted odds ratio $(\mathrm{AOR})=2.308 ; 95 \%$ confidence interval $(\mathrm{CI})=1.009-5.281)$. During the lockdown, however, no statistically significant difference was found between males and females in respect of PIU. The table also shows that, before the lockdown, the respondents aged 16 to 18 years were 
twice as likely as those aged 10 to 12 years $(\mathrm{AOR}=2.159 ; 95 \% \mathrm{CI}=0.202-23.064)$ to develop PIU, and that, during the lockdown, they were seven times more likely than 10- to 12 -year-olds to develop PIU (AOR $=7.093 ; 95 \% \mathrm{CI}=2.393-21.023)$. In respect of school level, the adolescents in senior high school were found to be twice as likely as junior high school students to exhibit PIU before the lockdown (AOR = $2.142 ; 95 \% \mathrm{CI}=1.009-5.281$ ), and three times as likely during the lockdown (AOR $=3.228 ; 95 \% \mathrm{CI}=1.822-5.719)$.

Table 5: Sociodemographic determinants of PIU

\begin{tabular}{|c|c|c|c|c|c|}
\hline \multirow{2}{*}{$\begin{array}{c}\text { Determinants of } \\
\text { PIU pre-lockdown }\end{array}$} & $\begin{array}{c}\text { Unstan- } \\
\text { dardised } \\
\text { regression } \\
\text { coefficient }\end{array}$ & \multirow{2}{*}{$\begin{array}{c}\text { adjusted odds } \\
\text { ratio (AOR) }\end{array}$} & \multicolumn{2}{|c|}{$\begin{array}{c}\text { 95\% confidence interval } \\
\text { (CI) for AOR }\end{array}$} & \multirow{2}{*}{ p-value } \\
\cline { 4 - 6 } & & & Lower & Upper & \\
\hline Age group (years) & & 2.159 & 0.202 & 23.064 & 0.524 \\
\hline $10-12$ & 0.770 & 1.440 & 0.579 & 3.579 & 0.432 \\
\hline $13-15$ & 0.365 & 1 & & & \\
\hline $16-18$ & & & & & \\
\hline Sex & & 2.308 & 1.009 & 5.281 & $\mathbf{0 . 0 4 8}$ \\
\hline Male & 0.836 & 1 & & & \\
\hline Female & & & & & \\
\hline $\begin{array}{c}\text { Current enrolment } \\
\text { level }\end{array}$ & & & & & \\
\hline Junior high school & 0.762 & 2.142 & 0.696 & 6.592 & 0.184 \\
\hline Senior high school & & 1 & & & \\
\hline Number of siblings & & & & & \\
\hline Three or fewer & 0.753 & 2.123 & 0.935 & 4.821 & 0.072 \\
\hline Four or more & & 1 & & & \\
\hline
\end{tabular}




\begin{tabular}{|c|c|c|c|c|c|}
\hline \multirow{2}{*}{$\begin{array}{l}\text { Determinants of } \\
\text { PIU during lock- } \\
\text { down }\end{array}$} & \multirow{2}{*}{$\begin{array}{l}\text { Unstan- } \\
\text { dardised } \\
\text { regression } \\
\text { coefficient }\end{array}$} & \multirow{2}{*}{$\begin{array}{l}\text { adjusted odds } \\
\text { ratio (AOR) }\end{array}$} & \multicolumn{2}{|c|}{$\begin{array}{l}95 \% \text { confidence interval } \\
\text { (CI) for AOR }\end{array}$} & \multirow[b]{2}{*}{ p-value } \\
\hline & & & Lower & Upper & \\
\hline \multicolumn{6}{|l|}{ Age group (years) } \\
\hline $10-12$ & 1.959 & 7.093 & 2.393 & 21.023 & $<0.001$ \\
\hline $13-15$ & 0.671 & 1.956 & 0.966 & 3.961 & 0.062 \\
\hline $16-18$ & & 1 & & & \\
\hline \multicolumn{6}{|l|}{$\begin{array}{c}\text { Current enrolment } \\
\text { level }\end{array}$} \\
\hline Junior high school & 1.172 & 3.228 & 1.822 & 5.719 & $<0.001$ \\
\hline Senior high school & & 1 & & & \\
\hline \multicolumn{6}{|l|}{ Number of siblings } \\
\hline Three or fewer & 0.457 & 1.579 & 0.916 & 2.723 & 0.100 \\
\hline Four or more & & 1 & & & \\
\hline \multicolumn{6}{|l|}{ Father's age (years) } \\
\hline$<45$ & -0.258 & 0.773 & 0.354 & 1.687 & 0.517 \\
\hline$\geq 45$ & & 1 & & & \\
\hline \multicolumn{6}{|l|}{ Mother's age (years) } \\
\hline$<45$ & 0.136 & 1.145 & 0.656 & 1.998 & 0.633 \\
\hline$\geq 45$ & & 1 & & & \\
\hline \multicolumn{6}{|l|}{ Person lived with } \\
\hline Parent & -0.325 & 0.723 & 0.336 & 1.553 & 0.405 \\
\hline Guardian & & 1 & & & \\
\hline
\end{tabular}

Note: $\mathrm{p}$-values in bold indicate finding is statistically significant $(\mathrm{p}<0.05)$ 
Table 6 shows the correlations between time spent online per day (during the lockdown) and sociodemographic and other internet use variables. It was found that for every unit increase in age, there was a corresponding increase in daily time spent online. Also, an increase in the years in formal education increased the daily time spent online.

Table 6: Correlation of time spent online per day with sociodemographic and other internet use variables

\begin{tabular}{|c|c|c|}
\hline Variable & r & p-value* $^{*}$ \\
\hline Age & 0.277 & $<\mathbf{0 . 0 0 1}$ \\
\hline Current enrolment level & 0.168 & $\mathbf{0 . 0 0 1}$ \\
\hline Number of siblings & 0.116 & 0.025 \\
\hline Father's age & 0.127 & $\mathbf{0 . 0 1 4}$ \\
\hline Mother's age & 0.092 & 0.075 \\
\hline Hours of daily internet access & 0.593 & $<\mathbf{0 . 0 0 1}$ \\
\hline Age of onset of internet use & 0.036 & 0.587 \\
\hline
\end{tabular}

Note: $\mathrm{p}$-values in bold indicate finding is statistically significant $(\mathrm{p}<0.05)$

\section{Analysis, conclusions and recommendations}

We found that a complete ability to control/limit one's level of internet use (i.e., an absence of PIU) existed among many adolescents before the COVID-19 lockdown period. The reasons for this could be traced to their active engagement in academic and extramural activities while schools were open. However, during the lockdown, fewer adolescents maintained the complete ability to control/limit their level of internet use, and a rise in the prevalence of PIU during the lockdown period was identified. Thus, the compulsory stay-at-home conditions during the lockdown appear to have increased the risk of PIU among adolescents.

We also noted that an increase in the number of years spent in formal education increases the development of PIU among adolescents. This reveals a higher likelihood for the development of PIU among persons with more years of formal education compared to those with fewer years. However, we noted that adolescents aged 10 to 12 years were two times more likely to develop PIU compared to those aged 16 to 18 years in the period before the COVID-19 lockdown. During the COVID-19 lockdown, on the other hand, adolescents within this same age group (10 to 12 years) were seven times more likely to develop PIU. This may be the result of parents providing internet-enabled devices to their children to enhance their mental development. 
We identified the following reasons for PIU among adolescents during the COVID-19 lockdown: boredom, loneliness, idleness, pleasure gained from internet use, peer pressure, poor discipline, parental neglect, physical isolation, and the need for information and communication. This corroborates with findings that when faced with undesirable conditions, many adolescents use the internet as a remedy or strategy for easing the burden of boredom, loneliness, and physical isolation (Brown, 2006). Although this adaptive strategy presents emotional and physical challenges, the internet provides immediate but temporary relief from life's worries (Cakmak \& Gul, 2018).

An implication of our findings is that a lack of physical social relationships could lead to the development or worsening of PIU. Many academic institutions have opted for e-learning or home-based schooling due to the imposed lockdown on schools (Donohue \& Miller, 2020). This need for access to e-learning has contributed to increasing adolescents' use of the internet beyond the two hours of daily use as recommended by the Australian government (Hoare et al., 2016). This is because most academic programmes last for about three hours every day, with each session lasting about an hour. Undisciplined use of the internet can result, which can expose adolescents to X-rated sites or other platforms which are not age appropriate (Tahiroğlu et al., 2008; Hoare et al., 2016). Thus, more frequent use of the internet, regardless of whether it is under the guise of e-learning or communication or seeking information, can put adolescents at greater risk for PIU.

The suggestions provided by the respondents about ways of mitigating PIU among adolescents included educating adolescents about the threats that PIU can pose to their present and future lifestyle. Parental monitoring of internet use was also cited as a means by which internet use could be kept at more appropriate levels among adolescents. Parental monitoring does not necessary imply excessive parental intervention in internet use, but implies the regulation of internet use for adolescents. The controlled use of the internet has been associated with the development of positive and protective habits that can ensure that adolescents become responsible adults in the future (Cakmak \& Gul, 2018; Park et al., 2018).

Suspension of the school closures was also, quite reasonably, stated as a potential mitigating factor for PIU among adolescents. However, a precise public health approach is needed for the resumption of school activities (Donohue \& Miller, 2020). Adolescent engagement in more productive tasks could also contribute to the prevention of PIU during the COVID-19 lockdown. These tasks could include practical music, vocational, or writing skills. This finding therefore clarifies that PIU can be prevented if its prevention is seen as a responsibility of both adolescents and their parents/ guardians. 
In respect of the limitations of our study, it should be noted that, because this study was not conducted at the early stage of the COVID-19 outbreak in Nigeria, our findings could have been limited by recall bias. Also, the nature of this study could have concealed important knowledge that would have been obtained using a longitudinal study design.

It is our recommendation that healthy internet use interventions should commence with children at an early age, to strengthen the positive use of the internet during adolescence. Parents should regulate adolescents' access to the internet. Also, health education sessions on the risks of developing PIU through excessive internet usage should be communicated during health campaigns and should be broadcast on the media. In addition, further research needs to be conducted on the effects of PIU on adolescents' mental and psychological health.

\section{References}

Aboujaoude, E. (2010). Problematic Internet use: An overview. World Psychiatry, 9(2), 85-90. https://doi.org/10.1002/j.2051-5545.2010.tb00278.x

Afolabi, A. A., \& Ilesanmi, O. S. (2021). Dealing with vaccine hesitancy in Africa: The prospective COVID-19 vaccine context. The Pan African Medical Journal, 38(3). https://doi.org/10.11604/pamj.2021.38.3.27401

Ajayi, O. (2020, March 21). Covid-19: FG shuts Enugu, Port Harcourt and Kano Airports. Vanguard.

Brown, J. D. (2006). Emerging adults in a media-saturated world. In J.J. Arnett \& J. L. Tanner (Eds.), Emerging adults in America: Coming of age in the 21st century (pp. 279-299). American Psychological Association. https://doi.org/10.1037/11381-012

Cakmak, F. H., \& Gul, H. (2018). Factors associated with problematic internet use among children and adolescents with Attention Deficit Hyperactivity Disorder. Northern Clinics of Istanbul, 5(4), 302-313. https://doi.org/10.14744/nci.2017.92668

Ceyhan, A. A. (2008). Predictors of problematic Internet use on Turkish university students. Cyberpsychology \& Behaviour, 11, 363-366. https://doi.org/10.1089/cpb.2007.0112

Donohue, J. M., \& Miller, E. (2020). COVID-19 and school closures. JAMA, E1-E3. https://doi.org/10.1001/jama.2020.13092

Hoare, E., Millar, L., Fuller-Tyszkiewicz, M., Skouteris, H., Nichols, M., Malakellis, M., Swinburn, B., \& Allender, S. (2016). Depressive symptomatology, weight status and obesogenic risk among Australian adolescents: A prospective cohort study. BMJ Open, 6(3), e010072. https://doi.org/10.1136/bmjopen-2015-010072

Ilesanmi, O. S., Afolabi, A. A., Akande, A., Raji, T., \& Mohammed, A. (2021). Infection prevention and control during COVID-19 pandemic: Realities from healthcare workers in a northcentral state in Nigeria. Epidemiology and Infection, 149(e15), 1-9. https://doi.org/10.1017/S0950268821000017 
Király, O., Potenza, M. N., Stein, D. J., King, D. L., Hodgins, D. C., Saunders, J. B., Griffiths, M. D., Gjoneska, B., Billieux, J., \& Brand, M. (2020). Preventing problematic internet use during the COVID-19 pandemic: Consensus guidance. Comprehensive Psychiatry, 100. https://doi.org/10.1016/j.comppsych.2020.152180

Kormas, G., Critselis, E., Janikian, M., Kafetzis, D., \& Tsitsika, A. (2011). Risk factors and psychosocial characteristics of potential problematic and problematic internet use among adolescents: a cross-sectional study. BMC Public Health, 11, 595.

https://doi.org/10.1186/1471-2458-11-595

National Population Commission (NPC), \& ICF (2019). Nigeria demographic and health survey 2018. https://dhsprogram.com/pubs/pdf/FR359/FR359.pdf

Nigeria Centre for Disease Control (NCDC). (2020, September 11). COVID-19 situation report as at 23rd August 2020. https://covid19.ncdc.gov.ng/

Oshodi, O. Y., Erinfolami, A. R., \& Akinbode, A. A. (2012). Problematic internet usage among students in a medical school in Lagos, Nigeria. Nigerian Journal of Psychiatry, 10(1).

Park, M., Park, S., Jung, K., Kim, J. I., Cho, S. C., \& Kim, B. (2018). Moderating effects of depressive symptoms on the relationship between problematic use of the Internet and sleep problems in Korean adolescents. BMC Psychiatry, 1-8. https://doi.org/10.1186/s12888-018-1865-x

Tahiroğlu, A. Y., Çelik, G., Uzel, M., Özcan, N., \& Avci, A. (2008). Internet use among Turkish adolescents. Cyberpsychology, Behavior, and Social Networking, 11, 537-543. https://doi.org/10.1089/cpb.2007.0165

Üneri, Ö. Ş., \& Tanıdır, C. (2011). Evaluation of internet addiction in a group of high school students: a cross-sectional study [in Turkish]. Dusunen Adam: The Journal of Psychiatry and Neurological Sciences, 24, 265-272. https://doi.org/10.5350/DAJPN2011240402

Volkin, S. (2020, May 11). The impact of the COVID-19 pandemic on adolescents. https:// hub.jhu.edu/2020/05/11/covid-19-and-adolescents

World Health Organisation (WHO). (n.d.). Coronavirus. https://www.who.int/healthtopics/coronavirus\#tab=tab_1

Worldometer. (n.d.). Coronavirus. https://www.worldometers.info/coronavirus/

Yang, S. C., \& Tung, C. J. (2007). Comparison of internet addicts and non-addicts in Taiwanese high school. Computers in Human Behaviour, 23, 79-96.

Young, K. S., \& Rogers, R. C. (2009). The relationship between depression and internet addiction. Cyberpsychology, Behavior, and Social Networking, 1, 25-28. https://doi.org/10.1089/cpb.1998.1.25 


\section{Appendix: Questionnaire}

\begin{tabular}{|c|c|c|}
\hline \multicolumn{3}{|c|}{ Sociodemographic characteristics } \\
\hline 1. Age (last birthday): & 1. M & 2. F \\
\hline \multicolumn{3}{|l|}{ 3. Highest class attained: } \\
\hline 4. Who do you live with? & $\begin{array}{l}\text { 2. Guard- } \\
\text { ian }\end{array}$ & 3. Others (specify): \\
\hline \multicolumn{3}{|l|}{ 5. Father's highest educational qualification: } \\
\hline \multicolumn{3}{|l|}{ 6. Mother's highest educational qualification: } \\
\hline \multicolumn{3}{|l|}{ 7. Father's occupation: } \\
\hline \multicolumn{3}{|l|}{ 8. Mother's occupation: } \\
\hline 9. Family type & 2. Exten & ded \\
\hline \multicolumn{3}{|l|}{ 10. Number of siblings: } \\
\hline \multicolumn{3}{|l|}{ 11. Father's age: } \\
\hline \multicolumn{3}{|l|}{ 12. Mother's age: } \\
\hline \multicolumn{3}{|c|}{ Pattern of internet use } \\
\hline \multicolumn{3}{|c|}{$\begin{array}{l}\text { 13. Which of these devices do you currently own? } 1 \text {. Smartphone 2. Desktop 3. Laptop 4. Tablet } 5 . \\
\text { Gaming device }\end{array}$} \\
\hline \multicolumn{3}{|c|}{ 14. How many hours per day do you have internet access? } \\
\hline \multicolumn{3}{|l|}{ 15. Time spent online per day (specify): } \\
\hline \multicolumn{3}{|l|}{ 16. Age of onset of internet use (specify): } \\
\hline \multicolumn{3}{|c|}{$\begin{array}{l}\text { 17. Frequency of internet use } 1 \text {. Less than once a week 2.1-3 times a week 3.4-6 times a week } \\
\text { 4. Daily }\end{array}$} \\
\hline \multicolumn{3}{|c|}{$\begin{array}{l}\text { 18. Device used for internet access } 1 \text {. Smartphone } 2 . \text { Desktop 3. Laptop 4. Tablet } 5 \text {. Gaming } \\
\text { device }\end{array}$} \\
\hline \multicolumn{3}{|c|}{$\begin{array}{l}\text { 19. Internet point of access } 1 . \text { Home } 2 \text {. School } 3 \text {. Free public hotspots } 4 \text {. Paid hotspots } 5 \text {. Person- } \\
\text { al phone }\end{array}$} \\
\hline \multicolumn{3}{|c|}{$\begin{array}{l}\text { 20. Reason(s) for going online } 1 \text {. Communication 2. Socialization 3. School assignment 4. Infor- } \\
\text { mation research 5. Others (specify): }\end{array}$} \\
\hline \multicolumn{3}{|c|}{$\begin{array}{l}\text { 21. What have you done online in the past } 24 \text { hours? } 1 \text {. Watching movies/serials/videos } 2 \text {. Down- } \\
\text { loads } 3 \text {. Reading magazines/books } 4 \text {. Listening/watching music } 5 \text {. Online gaming } 6 \text {. Chatting with } \\
\text { friends } 7 \text {. Using e-mails } 8 \text {. Making phone calls } 9 \text {. Internet social networking }\end{array}$} \\
\hline \multicolumn{3}{|c|}{ 22. Parent's awareness of internet use 1 . None $\quad 2$. Good $\quad 3$. Very good } \\
\hline \multicolumn{3}{|c|}{$\begin{array}{l}\text { 23. Used internet social networking type 1. Facebook 2. WhatsApp 3. Instagram 4. Snapchat } 5 . \\
\text { Twitter 6. Eskimi }\end{array}$} \\
\hline \multicolumn{3}{|c|}{ 24. Do you perceive you have problematic internet use? 1 . Yes 2 . No } \\
\hline \multicolumn{3}{|c|}{$\begin{array}{l}\text { 25. What are the causes of problematic internet use among high school during the COVID-19 } \\
\text { lockdown? }\end{array}$} \\
\hline \multicolumn{3}{|c|}{$\begin{array}{l}\text { 26. What are the likely effects of problematic internet use on high school during the COVID-19 } \\
\text { lockdown? }\end{array}$} \\
\hline \multicolumn{3}{|c|}{$\begin{array}{l}\text { 27. What are the factors associated with increased internet use among high school during the } \\
\text { COVID-19 lockdown? }\end{array}$} \\
\hline
\end{tabular}


28. What can you suggest should be done to reduce problematic internet use among high school students during the COVID-19 lockdown period?

\section{Internet Addiction Test}

Key: 0: does not apply; 1: rarely; 2: occasionally; 3: frequently; 4: often; 5: always

\begin{tabular}{|c|c|c|c|c|c|c|c|}
\hline & \multirow[b]{2}{*}{ Questions } & \multicolumn{6}{|c|}{ Score } \\
\hline & & 0 & 1 & 2 & 3 & 4 & 5 \\
\hline \multirow[t]{2}{*}{1.} & $\begin{array}{l}\text { a. How often did you stay online longer than you intended before the } \\
\text { lockdown? }\end{array}$ & & & & & & \\
\hline & $\begin{array}{l}\text { b. How often did you stay online longer than you intended during the } \\
\text { lockdown? }\end{array}$ & & & & & & \\
\hline 2. & $\begin{array}{l}\text { a. How often did you neglect household chores to spend more time } \\
\text { online before the lockdown? } \\
\text { b. How often do you neglect household chores to spend more time } \\
\text { online during the lockdown? }\end{array}$ & & & & & & \\
\hline \multirow[t]{2}{*}{3.} & $\begin{array}{l}\text { a. How often did you lose sleep due to late night log-ins before the } \\
\text { lockdown? }\end{array}$ & & & & & & \\
\hline & $\begin{array}{l}\text { b. How often do you lose sleep due to late night log-ins during the } \\
\text { lockdown? }\end{array}$ & & & & & & \\
\hline \multirow[t]{2}{*}{4.} & $\begin{array}{l}\text { a. Before the lockdown, how often did you try to hide how long you've } \\
\text { been online? }\end{array}$ & & & & & & \\
\hline & $\begin{array}{l}\text { b. During the lockdown, how often do you try to hide how long you've } \\
\text { been online }\end{array}$ & & & & & & \\
\hline \multirow[t]{2}{*}{5.} & $\begin{array}{l}\text { a. Before the lockdown, how often did you feel depressed, moody, or } \\
\text { nervous when you're offline, which goes away when you're back online? }\end{array}$ & & & & & & \\
\hline & $\begin{array}{l}\text { b. During the lockdown, how often do you feel depressed, moody, or } \\
\text { nervous when you're offline, which goes away when you're back online? }\end{array}$ & & & & & & \\
\hline \multirow[t]{2}{*}{6.} & $\begin{array}{l}\text { a. Before the lockdown, how often did your school grades or work } \\
\text { suffer because of the amount of time you spend online? }\end{array}$ & & & & & & \\
\hline & $\begin{array}{l}\text { b. During the lockdown, how often do your school grades or work } \\
\text { suffer because of the amount of time you spend online? }\end{array}$ & & & & & & \\
\hline \multirow[t]{2}{*}{7.} & $\begin{array}{l}\text { a. Before the lockdown, how often did your job performance or pro- } \\
\text { ductivity suffer because of the internet? }\end{array}$ & & & & & & \\
\hline & $\begin{array}{l}\text { b. During the lockdown, how often does your job performance or } \\
\text { productivity suffer because of the internet? }\end{array}$ & & & & & & \\
\hline \multirow[t]{2}{*}{8.} & $\begin{array}{l}\text { a. Before the lockdown, how often did you become defensive or secre- } \\
\text { tive when anyone asks you what you do online? }\end{array}$ & & & & & & \\
\hline & $\begin{array}{l}\text { b. During the lockdown, how often do you become defensive or secre- } \\
\text { tive when anyone asks you what you do online? }\end{array}$ & & & & & & \\
\hline \multirow[t]{2}{*}{9.} & $\begin{array}{l}\text { a. Before the lockdown, how often did you check your e-mail before } \\
\text { something else that you need to do? }\end{array}$ & & & & & & \\
\hline & $\begin{array}{l}\text { b. During the lockdown, how often do you check your e-mail before } \\
\text { something else that you need to do? }\end{array}$ & & & & & & \\
\hline
\end{tabular}




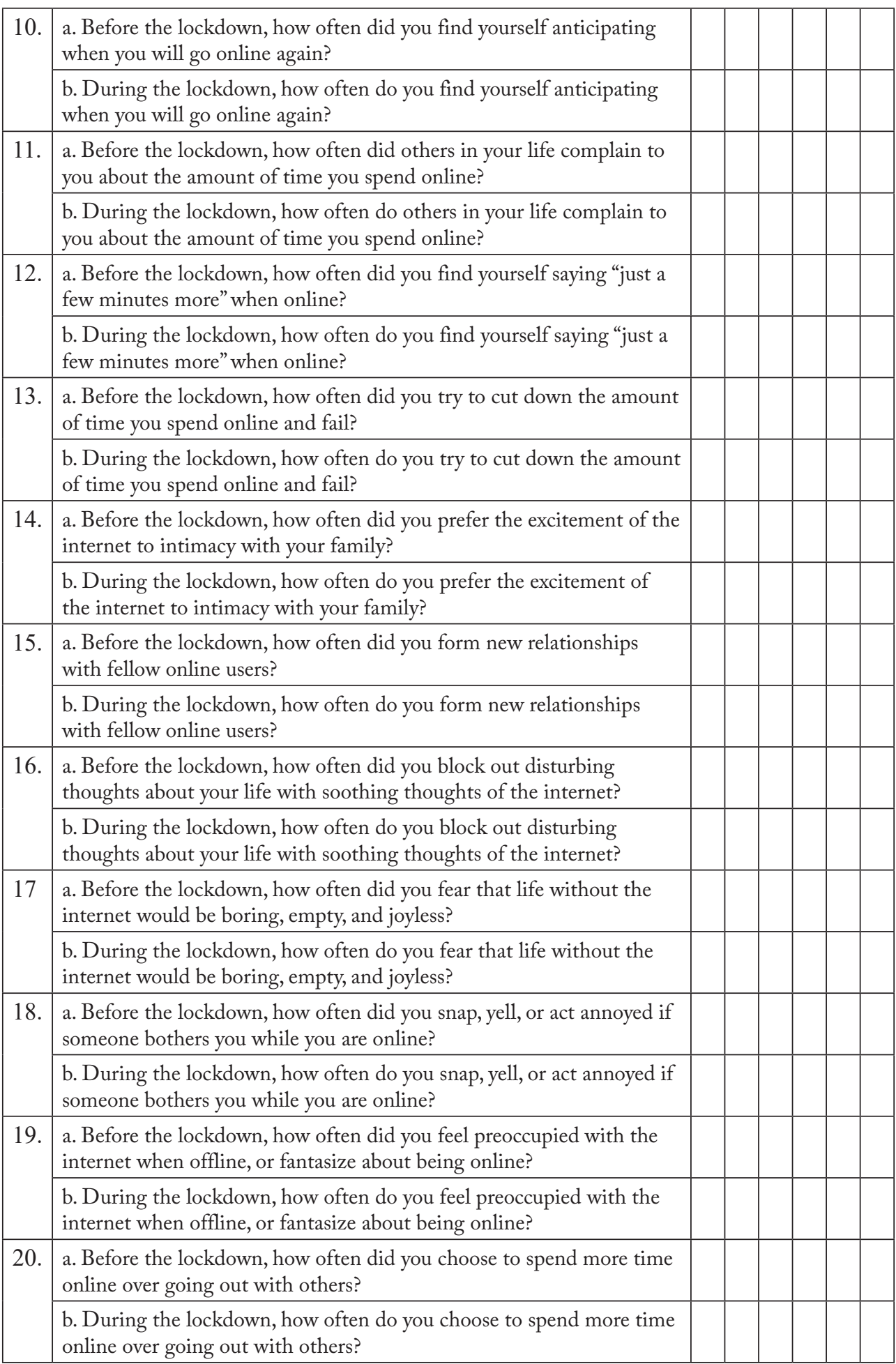

